\title{
Post-cardiac transplant survival after support with a continuous-flow left ventricular assist device: Impact of duration of left ventricular assist device support and other variables
}

\author{
Ranjit John, MD, ${ }^{\mathrm{a}}$ Francis D. Pagani, MD, ${ }^{\mathrm{b}}$ Yoshifumi Naka, MD, ${ }^{\mathrm{c}}$ Andrew Boyle, MD, ${ }^{\mathrm{a}}$ \\ John V. Conte, MD ${ }^{\mathrm{d}}$ Stuart D. Russell, MD, ${ }^{\mathrm{d}}$ Charles T. Klodell, MD, ${ }^{\mathrm{e}}$ Carmelo A. Milano, MD, ${ }^{\mathrm{f}}$ \\ Joseph Rogers, MD, ${ }^{\mathrm{f}}$ David J. Farrar, $\mathrm{PhD},{ }^{\mathrm{g}}$ and O. Howard Frazier, $\mathrm{MD}^{\mathrm{h}}$
}

\begin{abstract}
Objective: Although left ventricular assist devices (LVADs) are associated with excellent outcomes in patients with end-stage heart failure, there are conflicting reports on posttransplant survival in these patients. Furthermore, prior studies with pulsatile LVADs have shown that transplantation, either early ( $<6$ weeks) or late ( $>6$ months) after LVAD implantation, adversely affected post-cardiac transplant survival. We sought to determine factors related to posttransplant survival in patients supported with continuous-flow LVADs.
\end{abstract}

\begin{abstract}
Methods: The HeartMate II LVAD (Thoratec Corporation, Pleasanton, Calif) was implanted in 468 patients as a bridge to transplant at 36 centers in a multicenter trial. Patients who underwent transplantation after support were stratified by demographics: gender, age, etiology, body mass index, duration of device support, and by adverse events during support. The median age was 54 years (range $18-73$ years); $43 \%$ had ischemic etiology, and 18\% were women. Survival was determined at the specific intervals of 30 days and 1 year after transplantation.
\end{abstract}

\begin{abstract}
Results: Of 468 patients, $250(53 \%)$ underwent cardiac transplant after a median duration of LVAD support of 151 days (longest: 3.2 years), 106 (23\%) died, 12 (2.6\%) recovered ventricular function and the device was removed, and $100(21 \%)$ were still receiving LVAD support. The overall 30-day and 1-year posttransplant survivals were $97 \%$ and $87 \%$. There were no significant differences in survival based on demographic factors or LVAD duration of less than 30 days, 30 to 90 days, 90 to 180 days, and more than 180 days. Patients requiring more than 2 units of packed red blood cells in 24 hours during LVAD support had a statistically significant decreased 1-year survival ( $82 \%$ vs $94 \%$ ) when compared with patients who did not require more than 2 units of packed red blood cells in 24 hours during LVAD support $(P=.03)$. There was a trend for slightly lower survival at 1 year in patients with percutaneous lead infections during LVAD support versus no infection $(75 \%$ vs $89 \% ; P=.07)$.

Conclusions: Post-cardiac transplant survival in patients supported with continuous-flow devices such as the HeartMate II LVAD is equivalent to that with conventional transplantation. Furthermore, posttransplant survival is not influenced by the duration of LVAD support. The improved durability and reduced short- and long-term morbidity associated with the HeartMate II LVAD has reduced the need for urgent cardiac transplantation, which may have adversely influenced survival in the pulsatile LVAD era. This information may have significant implications for changing the current United Network for Organ Sharing criteria regarding listing of heart transplant candidates. (J Thorac Cardiovasc Surg 2010;140:174-81)
\end{abstract}

Heart transplantation is an established treatment modality for patients with advanced heart failure. ${ }^{1}$ An increasing number of patients are being successfully bridged to a heart transplant

From the Division of Cardiothoracic Surgery, ${ }^{a}$ University of Minnesota, Minneapolis, Minn; University of Michigan, ${ }^{b}$ Ann Arbor, Mich; Columbia University, ${ }^{\mathrm{c}}$ New York, NY; Johns Hopkins University, ${ }^{d}$ Baltimore, Md; University of Florida, ${ }^{\mathrm{e}}$ Gainesville, Fla; Duke University, ${ }^{\mathrm{f}}$ Durham, NC; Thoratec Corp, ${ }^{\mathrm{g}}$ Pleasanton, Calif; and Texas Heart Institute, ${ }^{\mathrm{h}}$ Houston, Tex.

Disclosures: Joseph Rogers, Francis Pagani, Stuart Russell, and Andrew Boyle report fees and grant support from Thoratec.

Read at the Eighty-ninth Annual Meeting of The American Association for Thoracic Surgery, Boston, Massachusetts, May 9-13, 2009.

Received for publication June 2, 2009; revisions received Jan 7, 2010; accepted for publication March 26, 2010; available ahead of print May 6, 2010.

Address for reprints: Ranjit John, MD, Division of Cardiothoracic Surgery, University of Minnesota, Minneapolis, MN 55455 (E-mail: johnx008@umn.edu).

$0022-5223 / \$ 36.00$

Copyright (c) 2010 by The American Association for Thoracic Surgery doi: $10.1016 /$ j.jtcvs. 2010.03 .037 with a left ventricular assist device (LVAD), with a smaller proportion receiving LVADs as destination therapy. ${ }^{2}$ Most patients who have undergone LVAD placement as a bridge to transplant (BTT) in the United States have been supported by pulsatile, volume-displacement devices such as the HeartMate XVE (Thoratec Corporation, Pleasanton, Calif). ${ }^{3,4}$ These devices provide excellent hemodynamic support and improve patient survivals, but they do have significant constraints, including the need for extensive surgical dissection, requirement for the patient to have a large body habitus, need for a large-diameter percutaneous lead, and audible pump operation. Importantly, long-term mechanical durability is limited, frequently resulting in reoperations for device exchange. The new HeartMate II LVAD, which incorporates continuous-flow rotary pump technology, represents the next generation of devices. Continuous-flow rotary 

Abbreviations and Acronyms
BTT = bridge to transplant
FDA $=$ Food and Drug Administration
LVAD $=$ left ventricular assist device
PRBCs $=$ packed red blood cells
UNOS $=$ United Network for Organ Sharing

pumps are thought to have enhanced durability and provide improved quality of life for extended periods of support. A major advantage of these new pumps is their small size, thereby extending therapy to underserved patient populations including women and even some children.

Although results with LVADs have consistently improved over time, several questions remain with regard to patient management and optimal timing of cardiac transplantation after initiation of LVAD support. ${ }^{5,6}$ The decision to proceed with heart transplantation after initiation of LVAD support is guided partly by variables not in full control of the transplant team, such as donor availability, United Network for Organ Sharing (UNOS) policy for listing, and patient-related variables such as blood group and body size. Ultimately, the decision to proceed with active listing lies with the transplant team, as is the decision to either accept or refuse a donor heart for the potential recipient. In recent years, significant UNOS policy changes affecting LVAD BTT candidates have occurred on the basis of outcomes data in patients supported with pulsatile devices. ${ }^{7}$ It is possible that additional changes can occur on the basis of the posttransplant survival outcomes in patients supported with the newer generation continuous-flow rotary devices.

Furthermore, although results using LVADs as BTT are similar to those in patients undergoing transplantation without LVAD support, there have been conflicting reports on the impact of LVADs on posttransplant survival..$^{8-13}$ Concerns have also been raised regarding the negative effects of return to full pulsatility after cardiac transplantation in patients supported with continuous-flow devices. ${ }^{14}$ Continuous-flow devices have rapidly become the standard of care when used as a BTT with excellent outcomes reported. ${ }^{15}$ However, limited data have been reported on the posttransplant survival in patients supported by continuous-flow devices. The objective of this study was to evaluate the influence of patient demographics, duration of LVAD support, and adverse events during LVAD support on posttransplant survival in patients supported by the HeartMate II LVAD.

The HeartMate II LVAD, a continuous-flow rotary pump with an axial blood flow path design, has recently concluded a Food and Drug Administration (FDA)-approved pivotal trial in 133 patients designed to evaluate outcomes at 6 months. ${ }^{15}$ Since that first report, 335 additional patients have undergone implantation of the HeartMate II LVAD as of April 2008 through a continued-access protocol approved by the FDA, and 250 have received transplants. We thereby report on the posttransplant survival results in patients who have undergone heart transplantation from this large observational clinical study using the HeartMate II LVAD as a BTT.

\section{PATIENTS AND METHODS Study Organization}

Patients were enrolled in the study conducted at 35 centers in the United States and Canada between March 2005 and April 2008. The study was supervised by the sponsor (Thoratec Corporation). Coordinators at each site collected all study data, which were then forwarded to the data analysis center of the sponsor. The academic authors vouch for the completeness and accuracy of the data and the analyses. A data and safety monitoring board, consisting of 4 independent physicians and 1 biostatician who were not investigators in the study, met routinely to review study compliance, adverse events, quality of life, and outcomes of patients. A clinical events committee of 4 independent physicians reviewed, classified, and adjudicated the causes of death and all adverse events. The study was conducted in compliance with FDA regulations for Good Clinical Practices. The protocol was approved by the FDA and the institutional review board at each participating center.

\section{Study Subjects}

Patients with end-stage heart failure and listed for heart transplantation at each center were eligible for study enrollment. Detailed inclusion and exclusion criteria have been previously presented. ${ }^{15}$ Patients were required to have New York Heart Association class IV heart failure symptoms and to be ill enough to have high priority for transplantation (UNOS status $1 \mathrm{~A}$ or 1B). Exclusion criteria included severe renal, pulmonary, or hepatic dysfunction, active uncontrolled infection, a mechanical aortic valve, aortic insufficiency, an aortic aneurysm, other mechanical circulatory support (except an intra-aortic balloon pump), and technical obstacles thought by the investigator to pose an increased surgical risk. All participating patients provided written informed consent.

\section{Baseline Assessment}

Baseline data were collected on demographics, health history, New York Heart Association functional class, blood chemistries, hematology data, neurologic status, and concomitant medications.

\section{HeartMate II LVAD}

The pump used in this study was the HeartMate II LVAD (Thoratec Corporation), which is a continuous-flow device consisting of an internal axial flow blood pump with a percutaneous lead that connects the pump to an external system driver and power source, which has been previous described. ${ }^{15}$ The pump contains an internal rotor with helical blades that curve around a central shaft. When the rotor spins on its axis, kinetic energy is imparted to the blood, which is drawn continuously from the left ventricular apex through the pump and into the ascending aorta. The pump has an implant volume of $63 \mathrm{~mL}$ and generates up to $10 \mathrm{~L} / \mathrm{min}$ of flow at a mean pressure of $100 \mathrm{~mm} \mathrm{Hg}$.

\section{Surgical Implantation}

Surgical implantation of the HeartMate II LVAS was conducted according to the HeartMate II LVAS Instructions for Use. Postoperative treatment included close monitoring of the patient's anticoagulation regimen.

\section{Postimplant Follow-up}

After device implantation, a standardized antithrombotic regimen was implemented with initiation of heparin followed by transition to warfarin 
as well as aspirin. Postoperative medical management, including inotropic, antiarrhythmic, and heart failure therapy, was performed according to each investigator's preference and usual practice.

\section{Posttransplant Follow-up}

After transplant, patients were followed up by centers based on each center's own routine posttransplant follow-up schedule. Each center completed a form to document 1-month and 1-year posttransplant survival. This study did not evaluate posttransplant complications such as rejection, infections, or readmissions.

Survival after transplantation was determined at 2 specific time points: 30 days and 1 year. Patients were stratified by demographic factors (age, gender, body mass index, and etiology of heart failure), the presence of adverse events during LVAD support (bleeding requiring more than 2 units of packed red blood cells (PRBCs) per any 24-hour period after LVAD implant, bleeding requiring reoperation, any infection adverse event during support, infection at the percutaneous lead exit site or pump pocket, renal dysfunction (last serum creatinine value $>1.7 \mathrm{mg} / \mathrm{dL}$ during support or blood urea nitrogen value $>30 \mathrm{mg} / \mathrm{dL}$ ), and hepatic dysfunction (last alanine aminotransferaase value $>40$ IU during support).

Survival after transplantation was also compared with the survival for patients continuing on LVAD support, starting at 6 months of support and continuing through 18 months of support (censored for transplantation).

\section{Statistical Analysis}

Differences between groups were determined with Fisher's exact test or the Pearson $\chi^{2}$ test where appropriate. All statistical comparisons are 2-sided.

\section{RESULTS \\ Study Patients}

A total of 468 patients who met study-entry criteria were enrolled into the study as of April 2008 and underwent implantation of the continuous-flow pump as a BTT. Of 468 patients, $250(53 \%)$ underwent cardiac transplantation and are the focus of this report. In addition, 106 (23\%) died, $12(2.6 \%)$ recovered ventricular function and the device was removed, and $100(21 \%)$ were still receiving LVAD support. Of the transplanted patients, 229 patients have completed a 30-day follow-up and 190 patients have completed a 1-year follow-up.

Baseline characteristics of the patients who underwent transplantation are shown in Table 1 . The majority of subjects were men with a median age of 54 years. The most frequent etiology of the heart failure was nonischemic cardiomyopathy. All patients had symptoms of advanced heart failure despite optimal medical management with oral medications. The majority of patients in the study were receiving inotropic therapy and those not receiving inotropic therapy at the time of LVAD implantation were intolerant to inotropic therapy owing to ventricular arrhythmias. Forty-six percent of patients were receiving concomitant support with an intraaortic balloon pump. A significant proportion had previously received biventricular pacing therapy. The majority of patients were listed at UNOS status 1A. Preoperative hemodynamic and laboratory assessment were consistent with a group of patients with advanced heart failure (Table 1).
TABLE 1. Baseline characteristics of the 250 LVAD patients who underwent heart transplantation

\begin{tabular}{|c|c|}
\hline Characteristic & $\begin{array}{c}\text { Mean } \pm \text { SD or } \\
\text { no. }(\%)(n=250)\end{array}$ \\
\hline Age $(y)$ & $51 \pm 13$ \\
\hline Male $(\%)$ & $204(82 \%)$ \\
\hline Body mass index $\left(\mathrm{kg} / \mathrm{m}^{2}\right)$ & $27 \pm 5.6$ \\
\hline Body surface area $\left(\mathrm{m}^{2}\right)$ & $2.0 \pm 0.3$ \\
\hline Ischemic etiology of heart failure ( $\%)$ & $107(43 \%)$ \\
\hline Left ventricular ejection fraction $(\%)$ & $16.1 \pm 6.5$ \\
\hline \multicolumn{2}{|l|}{ Arterial blood pressure $(\mathrm{mm} \mathrm{Hg})$} \\
\hline Systolic & $98.2 \pm 15.4$ \\
\hline Diastolic & $62.3 \pm 12.1$ \\
\hline Pulmonary capillary wedge pressure $(\mathrm{mm} \mathrm{Hg})$ & $25.4 \pm 8.2$ \\
\hline Cardiac index $\left(\mathrm{L} \cdot \mathrm{min}^{-1} \cdot \mathrm{m}^{-2}\right)$ & $2.1 \pm 0.7$ \\
\hline Heart rate (beats/min) & $92 \pm 18$ \\
\hline \multicolumn{2}{|l|}{ Pulmonary artery pressure $(\mathrm{mm} \mathrm{Hg})$} \\
\hline Systolic & $51.5 \pm 13.2$ \\
\hline Diastolic & $26.7 \pm 8.0$ \\
\hline Mean & $35.8 \pm 9.0$ \\
\hline Pulmonary vascular resistance (Wood units) & $2.8 \pm 1.4$ \\
\hline Central venous pressure (mm $\mathrm{Hg}$ ) & $12 \pm 6$ \\
\hline NYHA class & IV $(221 / 250)$ \\
\hline Serum sodium $(\mathrm{mmol} / \mathrm{L})$ & $133.3 \pm 5.2$ \\
\hline Serum albumin $(\mathrm{g} / \mathrm{dL})$ & $3.6 \pm 1.8$ \\
\hline Pre-albumin (mg/dL) & $18.5 \pm 7.7$ \\
\hline Cholesterol (mg/dL) & $129 \pm 41$ \\
\hline Serum creatinine $(\mathrm{mg} / \mathrm{dL})$ & $1.4 \pm 0.5$ \\
\hline Blood urea nitrogen $(\mathrm{mg} / \mathrm{dL})$ & $29.8 \pm 16.7$ \\
\hline ALT (IU/L) & $106 \pm 278$ \\
\hline AST (IU/L) & $91 \pm 223$ \\
\hline Total bilirubin $(\mathrm{mg} / \mathrm{dL})$ & $1.3 \pm 0.8$ \\
\hline $\mathrm{LDH}(\mathrm{mg} / \mathrm{dL})$ & $567 \pm 1538$ \\
\hline Hematocrit $(\%)$ & $34.8 \pm 5.7$ \\
\hline White blood count $(\times 1000 / \mathrm{mL})$ & $8.8 \pm 3.3$ \\
\hline Platelets $(1000 / \mathrm{mL})$ & $225 \pm 87$ \\
\hline International normalized ratio & $1.3 \pm 0.3$ \\
\hline \multicolumn{2}{|l|}{ Concomitant medications } \\
\hline Intravenous inotrope agents & $228(91 \%)$ \\
\hline Intolerant to inotropes owing to arrhythmias & $22(9 \%)$ \\
\hline Biventricular pacemaker & $119(48 \%)$ \\
\hline ICD & $192(77 \%)$ \\
\hline IABP & $115(46 \%)$ \\
\hline Mechanical ventilation & $18(7 \%)$ \\
\hline
\end{tabular}

$\overline{L V A D}$, Left ventricular assist device; $S D$, standard deviation; $N Y H A$, New York Heart Association; $A L T$, serum alanine aminotransaminase; $A S T$, serum aspartate aminotransaminase; $L D H$, lactate dehydrogenase; $I C D$, implantable cardioverter-defibrillator; $I A B P$, intra-aortic balloon pump.

\section{Outcomes}

Posttransplant survival. Of 468 patients, $250(53 \%)$ underwent cardiac transplantation after a median duration of LVAD support of 151 days (longest: 3.2 years). Of the patients undergoing transplantation, 229 patients have completed a 30-day follow-up and 190 have completed a 1-year follow-up.

Overall 30 -day and 1-year survivals are $97 \%$ and $87 \%$, respectively. The 1-year survival was $88 \%$ for men and 
TABLE 2. Posttransplant survival versus patient demographics

\begin{tabular}{|c|c|c|c|c|c|c|}
\hline & Demographic & LVAD duration & Survival at 30 days & $P$ value & Survival at 1 year & $P$ value \\
\hline Overall & All & $151(3.2 \mathrm{y})$ & $222 / 229(97 \%)$ & & $165 / 190(87 \%)$ & \\
\hline \multirow[t]{2}{*}{ Etiology } & Ischemic & $152(1.7 \mathrm{y})$ & $100 / 102(98 \%)$ & .47 & $74 / 85(87 \%)$ & 1.00 \\
\hline & Nonischemic & $143(3.2 y)$ & $122 / 127(96 \%)$ & & $91 / 105(87 \%)$ & \\
\hline \multirow[t]{2}{*}{ Gender } & Male & $145(3.2 \mathrm{y})$ & $182 / 187(97 \%)$ & .36 & $136 / 155(88 \%)$ & .41 \\
\hline & Female & $159(1.7 \mathrm{y})$ & $38 / 40(95 \%)$ & & $28 / 34(82 \%)$ & \\
\hline \multirow[t]{3}{*}{ Age (y) } & $<50$ & $131(3.2 \mathrm{y})$ & $82 / 85(97 \%)$ & .92 & $66 / 75(88 \%)$ & .93 \\
\hline & $50-59$ & $172(3.2 \mathrm{y})$ & 79/81 (98\%) & & $56 / 65(86 \%)$ & \\
\hline & $\geq 60$ & $151(1.8 \mathrm{y})$ & $61 / 63(97 \%)$ & & $43 / 50(86 \%)$ & \\
\hline \multirow[t]{3}{*}{ Body mass index } & $<20$ & $131(1.4 \mathrm{y})$ & $19 / 21(91 \%)$ & .10 & $16 / 19(84 \%)$ & .75 \\
\hline & $20-29$ & $136(3.2 y)$ & $136 / 138(99 \%)$ & & $99 / 112(88 \%)$ & \\
\hline & $\geq 30$ & $173(3.2 \mathrm{y})$ & $66 / 69(96 \%)$ & & $50 / 59(85 \%)$ & \\
\hline
\end{tabular}

$L V A D$, Left ventricular assist device.

$82 \%$ for women. There were no statistically significant differences in 30-day and 1-year posttransplant survivals among these patients when stratified by demographics including age, gender, etiology of heart failure, and body mass index (Table 2).

The patients undergoing transplantation were also stratified into 4 groups on the basis of duration of LVAD support ranging from less than 30 days to more than 180 days. There were no significant differences in either 30-day or 1-year posttransplant survivals among the 4 groups (Table 3 ). There was also no significant difference in either 30-day or 1-year posttransplant survivals when patients supported for more than 180 days were subdivided into 180 to 365 days and more than 365 days (Table 4).

Last, posttransplant survival was also stratified on the basis of the occurrence of adverse events during LVAD support as well as end-organ function before transplantation (Table 5). Patients requiring more than 2 units of PRBCs in 24 hours during LVAD support had a statistically significantly decreased 1-year survival $(82 \%$ vs $94 \%)$ when compared with patients who did not require more than 2 units of PRBCs in 24 hours during LVAD support $(P=.03)$. There was a trend for slightly lower survival at 1 year $(75 \%)$ in 28 patients with percutaneous lead infections during LVAD support versus no infection $(89 \%)(P=.07)$ and in 15 patients in whom the last creatinine level before transplant was more than $1.7 \mathrm{mg} / \mathrm{dL}(73 \%$ vs $88 \%)$ when compared with patients in whom the creatinine level before transplant was less than $1.7 \mathrm{mg} / \mathrm{dL}(P=.12)$. However, there were no statistically significant differences in 30-day or 1-year posttransplant survivals among the other groups, as shown in Table 5.
Posttransplant survival versus survival after 6 months of LVAD support. The 30-day and 1-year survivals for patients continuing on LVAD support (starting from 6 months of support, through 18 months, and censored for transplantation) were $98 \%$ and $87 \%$. This was not statistically significantly different from the 30-day and 1-year posttransplant survivals of $97 \%$ and $87 \%$. We used a starting point of 6 months for this analysis inasmuch as the median duration for timing of transplant on LVAD support was 151 days.

\section{DISCUSSION}

The discrepancy between the limited availability of donor hearts and the ever-increasing number of patients with heart failure has led to the increasing use of LVADs as a BTT. The use of mechanical circulatory support as BTT has evolved to become the standard of care in most cardiac transplant programs. However, several studies report that BTT with ventricular assist devices may reduce posttransplant survival. ${ }^{8-13}$ The findings from this study support and validate the use of the HeartMate II as BTT. These acceptable posttransplant survival data are closely linked to the outcomes during HeartMate II LVAD support that have been previously published. ${ }^{15}$

Patients with LVAD support who received more than 2 units of PRBCs in 24 hours during LVAD support had a significantly reduced 1-year posttransplant survival. The relationship between blood transfusions and increased morbidity and mortality in patients undergoing cardiac surgery is widely known. ${ }^{16}$ Whether this is because of the relationship between the use of blood products and an increased

TABLE 3. Posttransplant survival versus LVAD duration

\begin{tabular}{|c|c|c|c|c|c|}
\hline LVAD duration & Median days (maximum) & Survival at 30 days & $P$ value & Survival at 1 year & $P$ value \\
\hline$<30$ days & $18(28)$ & $17 / 17(100 \%)$ & .28 & $16 / 17(94 \%)$ & .18 \\
\hline 30-89 days & $58(89)$ & $62 / 62(100 \%)$ & & $55 / 59(93 \%)$ & \\
\hline 90-179 days & 135 (179) & $57 / 60(95 \%)$ & & $46 / 55(84 \%)$ & \\
\hline$\geq 180$ days & $258(3.2 \mathrm{yr})$ & $86 / 90(96 \%)$ & & $48 / 59(81 \%)$ & \\
\hline
\end{tabular}


TABLE 4. Posttransplant survival versus LVAD duration

\begin{tabular}{|c|c|c|c|c|c|}
\hline LVAD duration & Median days (maximum) & Survival at 30 days & $P$ value & Survival at 1 year & $P$ value \\
\hline$<30$ days & $18(28)$ & $17 / 17(100 \%)$ & .22 & $16 / 17(94 \%)$ & .28 \\
\hline 30-89 days & $58(89)$ & $62 / 62(100 \%)$ & & $55 / 59(93 \%)$ & \\
\hline 90-179 days & $135(179)$ & $57 / 60(95 \%)$ & & $46 / 55(84 \%)$ & \\
\hline 180-365 days & $227(363)$ & $64 / 68(94 \%)$ & & $37 / 45(82 \%)$ & \\
\hline$>365$ days & 507 (3.2 yr) & $22 / 22(100 \%)$ & & $11 / 14(79 \%)$ & \\
\hline
\end{tabular}

$L V A D$, Left ventricular assist device.

incidence of sensitization as well as infections is unclear from this study, although these relationships have been widely characterized, as shown in the next section.

Although the development of circulating antibodies, termed "sensitization," does not affect early perioperative LVAD-related morbidity and mortality, it has significant adverse effects, especially on posttransplant outcomes. ${ }^{17}$ Prior experience with pulsatile devices has been associated with a greater than $50 \%$ incidence of sensitization from some studies. ${ }^{16}$ The increased use of blood products during LVAD placement is reported to be a significant risk factor for the development of sensitization. ${ }^{18}$ The decreased posttransplant survival in LVAD patients in this study who received more than 2 units of PRBCs during LVAD support may be related to the adverse impact of sensitization. Interestingly, LVAD-related infections may also contribute to the development of sensitization. As a result of these circulating antibodies, LVAD recipients have a high likelihood of repeated donor-specific $\mathrm{T}$ cell cross-match reactivity, with the consequence of increased waiting time to transplantation. Thus, it is may not be uncommon for sensitized patients to receive a suboptimal donor inasmuch as the opportunity to obtain an immunologic compatible donor is low. The trend toward slightly increased mortality in patients supported for more than 12 months (although not significant) could be related to sensitization, because sensitized patients tend to wait longer for an immunologically compatible donor. Thus, although we did not measure the level of preformed antibodies in the patients receiving a HeartMate II device in this study, prior studies do point to the possibility of sensitization (from possible blood use and infections) on decreased posttransplant survival. ${ }^{19}$

The incidence of LVAD-related infection in the multicenter study was low, although the incidence increased after 30 days of support. ${ }^{15,20}$ The impact of infections during LVAD support on posttransplant outcomes is also controversial. ${ }^{21}$ It

TABLE 5. Posttransplant survival versus adverse events during LVAD support

\begin{tabular}{|c|c|c|c|c|c|c|}
\hline \multicolumn{2}{|c|}{ Adverse event } & \multirow{2}{*}{$\begin{array}{l}\text { LVAD duration } \\
120(3.2 \mathrm{y}) \\
\end{array}$} & \multirow{2}{*}{$\begin{array}{c}\text { Survival at } 30 \text { days } \\
132 / 135(98 \%) \\
\end{array}$} & \multirow{2}{*}{$\frac{P \text { value }}{.45}$} & \multirow{2}{*}{$\frac{\text { Survival at } 1 \text { year }}{102 / 115(89 \%)}$} & \multirow{2}{*}{$\frac{P \text { value }}{.38}$} \\
\hline Any infection & No & & & & & \\
\hline during LVAD support & Yes & $192(2.1 \mathrm{y})$ & $90 / 94(96 \%)$ & & $63 / 75(84 \%)$ & \\
\hline \multirow{2}{*}{$\begin{array}{l}\text { Percutaneous lead } \\
\text { infection during LVAD } \\
\text { support }\end{array}$} & No & $126(3.2 y)$ & $185 / 189(98 \%)$ & \multirow[t]{2}{*}{.10} & $144 / 162(89 \%)$ & \multirow[t]{2}{*}{.07} \\
\hline & Yes & $253(2.1 \mathrm{y})$ & $37 / 40(93 \%)$ & & $21 / 28(75 \%)$ & \\
\hline \multirow{2}{*}{$\begin{array}{l}\text { Reoperation for bleeding } \\
\text { during LVAD support }\end{array}$} & No & $149(3.2 \mathrm{y})$ & $180 / 184(98 \%)$ & \multirow[t]{2}{*}{.14} & $133 / 152(88 \%)$ & \multirow[t]{2}{*}{.60} \\
\hline & Yes & $152(3.2 \mathrm{y})$ & $42 / 45(93 \%)$ & & $32 / 38(84 \%)$ & \\
\hline \multirow{2}{*}{$\begin{array}{l}\text { Bleeding requiring }>2 \mathrm{U} \\
\text { PRBC/24 h during LVAD } \\
\text { support }\end{array}$} & No & $130(2.1 \mathrm{y})$ & $88 / 90(98 \%)$ & \multirow[t]{2}{*}{.71} & $74 / 79(94 \%)$ & \multirow[t]{2}{*}{.03} \\
\hline & Yes & $162(3.2 \mathrm{y})$ & $134 / 139(96 \%)$ & & $91 / 111(82 \%)$ & \\
\hline \multirow{2}{*}{$\begin{array}{l}\text { Last creatinine } \\
\text { value during LVAD support }\end{array}$} & $<1.7 \mathrm{mg} / \mathrm{dL}(1.1 \pm 0.1)$ & $143(3.2 y)$ & $202 / 209(97 \%)$ & \multirow[t]{2}{*}{1.00} & $154 / 175(88 \%)$ & \multirow[t]{2}{*}{.12} \\
\hline & $\geq 1.7 \mathrm{mg} / \mathrm{dL}(2.2 \pm 0.5)$ & $194(1.5 \mathrm{y})$ & $20 / 20(100 \%)$ & & $11 / 15(73 \%)$ & \\
\hline \multirow{2}{*}{$\begin{array}{l}\text { Last blood } \\
\text { urea nitrogen value } \\
\text { during LVAD support }\end{array}$} & $<30 \mathrm{mg} / \mathrm{dL}(17 \pm 5)$ & $143(3.2 y)$ & $200 / 206(97 \%)$ & \multirow[t]{2}{*}{.53} & $151 / 172(88 \%)$ & \multirow[t]{2}{*}{.27} \\
\hline & $\geq 30 \mathrm{mg} / \mathrm{dL}(46 \pm 19)$ & $178(1.3 \mathrm{y})$ & $22 / 23(96 \%)$ & & $14 / 18(78 \%)$ & \\
\hline \multirow{2}{*}{$\begin{array}{l}\text { Last ALT value } \\
\text { during LVAD support }\end{array}$} & $<40 \mathrm{IU}(24 \pm 8)$ & $157(3.2 \mathrm{y})$ & $171 / 177(97 \%)$ & \multirow[t]{2}{*}{1.00} & $124 / 142(87 \%)$ & \multirow[t]{2}{*}{.81} \\
\hline & $\geq 40 \mathrm{IU}(62 \pm 38)$ & $120(1.8 \mathrm{y})$ & $51 / 52(98 \%)$ & & $41 / 48(85 \%)$ & \\
\hline
\end{tabular}

$L V A D$, Left ventricular assist device; $P R B C$, packed red blood cell; $A L T$, serum alanine aminotransaminase; $A S T$, serum aspartate aminotransaminase. 
should be noted that there is an increasing incidence of driveline infection with increased duration of support, with one study reporting an incidence of $94 \%$ at 1 year of support with pulsatile devices. ${ }^{22}$ Although the overall incidence of driveline infections with the HeartMate II LVAD was low, ${ }^{15}$ in this study, there was a trend toward poorer survival $(P=.07)$ in patients undergoing transplantation with a driveline infection. There was also a trend toward slightly reduced survival (not significant) in patients supported for more than 12 months (11/14, 79\% 1-year survival). Of the 14 patients in this group, there were 8 with driveline infections, including all 3 patients who died and 5 of the 11 who survived. Patients with LVAD-related infections are known to wait longer for a heart transplant, presumably delayed by the need for often prolonged antibiotic therapy. Although significant progress has been made with LVAD-related infections, continued research is critical to further reduce and even eliminate driveline-related infections.

The development of right ventricular failure after LVAD implantation is also associated not only with reduced success of BTT but also with increased posttransplant mortality. The multicenter pivotal study has reported a significantly reduced incidence of right ventricular failure after HeartMate II implantation. ${ }^{15,23}$ The development of right ventricular failure after LVAD implantation is sometimes associated with an increased urgency for transplantation and thereby a tendency to use suboptimal donors for transplant. The lower incidence of right ventricular failure seen with the HeartMate II LVAD might also have contributed to the improved posttransplant survival.

Durability and reliability of LVAD design is perhaps one of the most significant features for extended use of mechanical circulatory support devices. Previous studies have demonstrated limited durability and reliability of the pulsatile HeartMate XVE LVAD, with nearly $50 \%$ of patients requiring device exchange owing to infection or mechanical malfunction at 18 months. ${ }^{24}$ Very few device replacements were required for device thrombosis and infection in the HeartMate II pivotal study. No mechanical failures of the device pumping mechanism were observed. ${ }^{15}$ The absence of mechanical failures of the pumping mechanism is significant and has not been previously observed in trials evaluating older technology. ${ }^{15}$ The remarkable durability of the HeartMate LVAD can allow for improved donor selection as opposed to the pulsatile pump era, in which decreasing durability beyond the 1-year mark increased the urgency for transplantation and a subsequent potential for suboptimal donor selection. The 87\% 1-year survival for patients receiving LVAD support (starting from 6 months of support), which is similar to the 1-year posttransplant survival, supports that at least in the short-term follow-up, optimizing donor selection is feasible with the HeartMate II LVAD.

Our data may have significant implications for changing the current UNOS criteria regarding listing of LVAD- bridged heart transplant candidates. In the previous HeartMate XVE era, changes in UNOS policy significantly affected LVAD-bridged candidates. Although further data with longer-term follow-up is essential to make definitive recommendations, our data might suggest whether patients in stable condition with a HeartMate II LVAD should be listed as a UNOS status IA in the absence of any LVADrelated complications. ${ }^{7,25}$

More relevant to this study is a recent report that a prolonged duration of support with continuous-flow devices may be associated with greater hemodynamic compromise, as demonstrated by the need for higher dose requirements and increased duration of pressor support after restoration of pulsatility at the time of transplantation. ${ }^{14}$ Although it should be noted that the later study showed no differences in early posttransplant mortality when compared with patients receiving pulsatile devices, there are studies that have noted differences in vascular tone and endothelial function in patients supported with continuous-flow devices. ${ }^{26}$

\section{Limitations}

A number of limitations are important in the interpretation of data from this present study. The study was nonrandomized with no real risk-adjusted group for direct comparison, although comparing the efficacy of LVADs as a BTT therapy with a medical control group would be considered unethical. Also, some important variables that were not examined in this study but could potentially influence transplant survival include HLA sensitization and pulmonary vascular resistance. There are also no data evaluated on posttransplant morbidity such as rejections, infections, and posttransplant length of stay and hospital readmissions. This study also had a limited 1-year posttransplant follow-up. Importantly, the causes of posttransplant death were unknown; this information could have shed light on the trend toward increased mortality in patients supported with the HeartMate II LVAD with percutaneous lead infections that underwent transplantation.

In summary, the HeartMate II LVAD as a BTT provides 1-year posttransplant survival that appears similar to that of conventional transplantation. Importantly, no differences in posttransplant survival were found when patients were stratified on the basis of duration of LVAD support as well as other demographic variables and post-LVAD adverse events. However, the increased use of blood transfusions during LVAD support significantly reduced transplant survival with a trend toward reduced posttransplant survival in patients with driveline infections. Further evaluation is necessary to understand the association with increased posttransplant mortality in the LVAD patients experiencing these later adverse events. Thus, there is no reason to support any hypothesis that the reduced pulsatility associated with continuous-flow devices such as the HeartMate II has any adverse impact on posttransplant survival. In conclusion, 
duration of support with the HeartMate II LVAD does not affect posttransplant survival, unlike the earlier experience with patients supported with pulsatile devices.

\section{References}

1. Taylor DO, Edwards LB, Aurora P, Christie JD, Dobbels F, Kirk R, et al. Registry of the International Society for Heart and Lung Transplantation: twenty-fifth official adult heart transplant report-2008. J Heart Lung Transplant. 2008;27: 943-56.

2. Frazier OH, Rose EA, Oz MC, Dembitsky W, McCarthy P, Radovancevic B, et al. Multicenter clinical evaluation of the HeartMate vented electric left ventricular assist system in patients awaiting heart transplantation. J Thorac Cardiovasc Surg. 2001;122:1186-95

3. Frazier OH, Rose EA, McCarthy P, Burton NA, Tector A, Levin H, et al. Improved mortality and rehabilitation of transplant candidates treated with a long-term implantable left ventricular assist system. Ann Surg. 1995;222: 327-36; discussion 336-8.

4. Farrar DJ, Hill JD, Pennington DG, McBride LR, Holman WL, Kormos RL, et al. Preoperative and postoperative comparison of patients with univentricular and biventricular support with the Thoratec ventricular assist device as a bridge to heart transplantation. J Thorac Cardiovasc Surg. 1997;113:202-9.

5. Gammie JS, Edwards LB, Griffith BP, Pierson RN 3rd, Tsao L. Optimal timing of cardiac transplantation after ventricular assist device implantation. J Thorac Cardiovasc Surg. 2004;127:1789-99.

6. Ashton RC Jr, Goldstein DJ, Rose EA, Weinberg AD, Levin HR, Oz MC. Duration of left ventricular assist device support affects transplant survival. $J$ Heart Lung Transplant. 1996;15:1151-7.

7. Renlund DG, Taylor DO, Kfoury AG, Shaddy RS. New UNOS rules: historical background and implications for transplantation management. J Heart Lung Transplant. 1999; 18:1065-70.

8. Patolla V, Patten RD, DeNofrio D, Konstam MA, Krishnamani R. The effect of ventricular assist devices on post-transplant mortality. An analysis of the United Network for Organ Sharing Thoracic Registry. J Am Coll Cardiol. 2009; 153:264-71.

9. Cleveland JC, Grover FL, Fullerton DA, Campbell DN, Mitchell MB, Lindenfeld $\mathrm{J}$, et al. Left ventricular assist device as bridge to transplantation does not adversely affect one-year transplantation survival. J Thorac Cardiovasc Surg. 2008;136:774-7.

10. Jaski BE, Kim JC, Naftel DC, Jarcho J, Costanzo MR, Eisen HJ, et al. Cardiac transplant outcome of patients supported on left ventricular assist device vs intravenous inotrope therapy. J Heart Lung Transplant. 2001;20:449-56.

11. Morgan JA, Park Y, Kherani AR, Vigilance DW, Cheema FH, Oz MC, et al. Does bridging to transplantation with a left ventricular assist device adversely affect posttransplantation survival? A comparative analysis of mechanical versus inotropic support. J Thorac Cardiovasc Surg. 2003;126:1180-90.

12. Aaronson KD, Eppinger MJ, Dyke DB, Wright S, Pagani FD. Left ventricular assist device therapy improves utilization of donor hearts. J Am Coll Cardiol. 2002; 39:1247-54.

13. Robertson JO, Lober C, Smedira NG, Navia JL, Sopko N, GonzalezStawinski GV. One hundred days or more bridged on a ventricular assist device and effects on outcomes following heart transplantation. Eur J Cardiovasc Surg. 2008;34:295-300.

14. Stewart AS, Russo MJ, Martens TP, Naseem TM, Deng MC, Wang R, et al. Longer duration of continuous-flow ventricular assist device support predicts greater hemodynamic compromise after return to pulsatility. J Thorac Cardiovasc Surg. 2008; 136:524-5.

15. Miller LW, Pagani FD, Russell SD, John R, Boyle AJ, Aaronson KD, et al. Use of a continuous-flow device in patients awaiting heart transplantation. $N$ Engl J Med. 2007;357:885-96.

16. Koch CG, Li L, Duncan AI, Mihaljevic T, Cosgrove DM, Loop FD, et al. Morbidity and mortality risk associated with red blood cell and blood-component transfusion in isolated coronary artery bypass grafting. Crit Care Med. 2006; 34:1608-16.

17. John R, Lietz K, Schuster M, Naka Y, Rao V, Mancini D, et al. Immunologic sensitization in recipients of left ventricular assist devices. J Thorac Cardiovasc Surg. 2003;125:578-91.

18. Moazami N, Itescu S, Williams M, Argenziano M, Weinberg A, Oz M. Platelet transfusions are associated with the development of anti-major histocompatibility complex class I antibodies in patients with left ventricular assist device support. J Heart Lung Transplant. 1998;17:876-80.
19. Nwakanma LU, Williams JA, Weiss ES, Russell SD, Baumgartner WA, Conte JV. Influence of pretransplant panel-reactive antibody on outcomes in 8190 heart transplant recipients in recent era. Ann Thorac Surg. 2007;84:1556-62.

20. Pagani FD, Miller LW, Russell SD, Aaronson KD, John R, Boyle AJ, et al. Extended mechanical circulatory support with a continuous-flow rotary ventricular assist device. J Am Coll Cardiol. 2009;51:312-21.

21. Schulman AR, Martens TP, Russo MJ, Christos PJ, Gordon RJ, Lowy FD, et al. Effect of left ventricular assist device infection on post-transplant outcomes. $J$ Heart Lung Transplant. 2009;28:237-42.

22. Zierer A, Melby SJ, Voeller RK, Guthrie TJ, Ewald GA, Shelton K, et al. Lateonset driveline infections: The Achilles' heel of prolonged left ventricular assist device support. Ann Thorac Surg. 2007;84:515-21.

23. Kormos RL, Teuteberg JJ, Pagani FD, Russell SD, John R, Miller LW, et al. Right ventricular failure in patients with the HeartMate II continuous-flow left ventricular assist device: incidence, risk factors, and effect on outcomes. J Thorac Cardiovasc Surg. 2010 Feb 2 [Epub ahead of print].

24. Dembitsky WP, Tector AJ, Park S, Moskowitz AJ, Gelijns AC, Ronan NS, et al. Left ventricular assist device performance with long term circulatory support: lessons from the REMATCH trial. Ann Thorac Surg. 2004;78:2123-30.

25. Morgan JA, Mazzeo PA, Flannery MR, Oz MC, Naka N. Effects of changes in UNOS policy regarding left ventricular assist devices. J Heart Lung Transplant. 2004;23:620-2.

26. Travis AR, Giridharan GA, Pantalos GM, Dowling RD, Prabhu SD, Slaughter MS, et al. Vascular pulsatility in patients with a pulsatile- or continuous-flow ventricular assist device. J Thorac Cardiovasc Surg. 2007;133:517-24.

\section{Discussion}

Dr James K. Kirklin (Birmingham, Ala). I have no financial disclosures to make.

I congratulate the authors on a very nice analysis of the HeartMate II experience as BTT therapy. This reflects the changing landscape that is occurring in mechanical support as the vast majority of devices now implanted are these smaller rotary pumps.

My first question relates to driveline infection. As we know, the major Achilles' heel of this pump and others like it is the ongoing low risk, which continues to be constant over time, of driveline infections developing. You showed some potentially important information in that even though the $P$ value was .07 , the $75 \% 1$-year survival associated with patients who had driveline infections was perhaps important. In view of that, do you have plans to go back and specifically review the causes of death in that cohort of patients so that we can better clarify this issue?

Dr John. That is an important question. Yes, we do plan to. Luckily it is a small number of patients, about 14 or 15 , and we should be able to track that down. It would be important to identify whether these posttransplant deaths were specifically related to infection and, even more importantly, whether the microbiologic studies performed in these patients who may have died of sepsis showed that the bacteria identified were similar to the original bacteria isolated at the time of driveline infections.

I think the take-home message is that patients with driveline infections should be adequately treated with long-term intravenous antibiotic therapy before transplantation, and many of these patients in our experience need maintenance therapy with oral antibiotics until the time of transplantation, even though their driveline infection seems to be eradicated.

Dr Kirklin. My second and final question relates to duration of LVAD support. Your data indicate and you conclude that the duration of LVAD support no longer has any influence on posttransplant survival, and this obviously has important implications. I am still not totally comfortable with your analysis and your 
conclusions in that there was a small decrease, although nonsignificant, in survival for those patients who were supported greater than 6 months. Furthermore, most of these were basically univariate analyses.

Do you think it would be advisable to now go back and do a more detailed multivariable analysis looking at duration of support as a continuous variable and at possible interactions with other risk factors before concluding securely that extended LVAD support has no impact on intermediate-term or long-term survival after transplant? To follow up on that, on the basis of your analysis, would you currently recommend that the priority status for LVADs in obtaining donor hearts be eliminated because of your conclusion that there is no impact on duration and survival?

Dr John. Thank you. Those are very important comments. With increasing duration of LVAD support, 2 other variables occur with increased frequency in patients supported for longer than 6 months. First, there is an increasing incidence of driveline infections the longer patients are receiving LVAD support. Second, patients who are waiting a long time on LVAD support may be waiting because they are sensitized. The increased incidence of both of these variables may account for the slight decrease in posttransplant survival when patients are on LVAD support for longer durations. It is important, therefore, to do a multivariate analysis to identify the clinically significant variables-infection, sensitization, increased duration, or a combination of these risk factors.

Currently, patients on LVAD support are usually assigned 1B status on the UNOS list and then get upgraded to a $1 \mathrm{~A}$ status for a 1-month period after LVAD implantation. Most centers choose the timing of the upgrade to a $1 \mathrm{~A}$ status around the 2- to 6-month mark, depending on blood group, regional based waiting times, as well as clinical patient-related variables. As reported in this study, the median duration of support for LVAD patients before transplantation is about 150 days. This might suggest that there may be support for removal of the 1A status for a stable LVAD patient and only allow the special status of $1 \mathrm{~A}$ for $\mathrm{LVAD}$ patients who are experiencing an adverse complication such as infection, severe arrhythmias, or sensitization. I think upgrading to a 1A status for a stable LVAD patient at home who is doing clinically well comes into question, in light of the increasing durability of currently available LVADs.

Dr Kirklin. Very nice analysis. Thank you.

Dr Stephen J. Lahey (Brooklyn, NY). I was very interested to see that one of your adverse risk factors was blood transfusions. This is a very interesting topic, not just in your particular area but in all of cardiac surgery. Multiple groups, such as the Northern New England Consortium, have reported that blood transfusions are a very, very bad thing and do predict mortality. Perhaps it would it be helpful if we had some idea of the triggers for transfusion. You have 33 centers. There may be some centers that will transfuse at a hematocrit value of $24 \%$ or others at a hematocrit value of $28 \%$. This fact, in and of itself, can be a confounder as far as using "blood transfusion", as an adverse risk predictor.

Dr John. I agree. Our general policy at our center is to delay blood transfusions for as long as possible, even up to a hemoglobin value of $8 \mathrm{~g}$, because these patients could get sensitized with the next unit of blood, but that information is important. Unfortunately, that trigger is not going to be obtained because of the number of centers and variable triggers for each center. But that is important information, I agree.

Dr David H. Adams (New York, NY). I do not know whether you know the age of your transfusion, but a paper published last year from Cleveland showed the age of blood products also negatively affected survival, and it may be something worth looking at as well. 